\title{
Gibbs Films of Semi-Fluorinated Alkanes at the Surface of Alkane Solutions
}

\author{
Piotr Marczuk, Peter Lang, ${ }^{*}{ }^{\dagger}$ Gerhard H. Findenegg, Surinder K. Mehta, and \\ Martin Möller
}

Stranski Laboratorium für Physikalische und Theoretische Chemie, Technische Universität Berlin, Strasse des 17. J uni 112, 10623 Berlin, Germany

Received J anuary 31, 2002. In Final Form: J une 4, 2002

\begin{abstract}
Adsorbed monolayer phases of semi-fluorinated alkanes $\mathrm{F}\left(\mathrm{CF}_{2}\right)_{12}\left(\mathrm{CH}_{2}\right)_{\mathrm{m}} \mathrm{H}$ with $\mathrm{m}=12,14,16$, and 18 (denoted $\mathrm{F}_{12} \mathrm{H}_{\mathrm{m}}$ ) at the free surface of their solutions in $\mathrm{H}_{12}$ and $\mathrm{H}_{16}$ solvents (dodecane, bicyclohexyl, and hexadecane) werestudied by surfacetensi on measurements and surface-sensitiveX-ray techniques. Solutions in the two $\mathrm{H}_{12}$ solvents exhi bit sharp first-order phasetransitions from a gaslikestateat high temperature to a condensed state at lower temperatures. In the condensed film, the fluorocarbon blocks of the $\mathrm{F}_{12} \mathrm{H}_{\mathrm{m}}$ molecules are cl ose-packed in two-dimensional hexagonal arrays (cross-sectional area, ca. $28 \AA^{2}$ ), but the in-plane order is rather short ranged, having a positional correlation length of only ca. $20 \AA$. The electron density profiles $\rho_{\mathrm{e}} \mathrm{z}$ ) reveal that the mass centers of the fluorocarbon blocks are not aligned in a plane but distributed over a region of ca. 20-30 $\AA$. The short-range order of these films is attributed to the packing frustration of the different diameters of the fluorocarbon and hydrocarbon blocks of the $\mathrm{F}_{12} \mathrm{H}_{\mathrm{m}}$ molecules. Gibbs films of $\mathrm{F}_{12} \mathrm{H}_{16}$ on hexadecane exhibit not a sharp transition but a gradual increase of the surface concentration below $25^{\circ} \mathrm{C}$. This anomalous behavior is attributed tentatively to a solvation of the alkane block of the $\mathrm{F}_{12} \mathrm{H}_{16}$ molecules by the hydrocarbon solvent, which will prevent a close packing of the fluorocarbon blocks.
\end{abstract}

\section{Introduction}

Semi-fluorinated alkanes (SFA) of the general formula $\mathrm{F}\left(\mathrm{CF}_{2}\right)_{\mathrm{n}}\left(\mathrm{CH}_{2}\right)_{\mathrm{m}} \mathrm{H}$ (denoted $\mathrm{F}_{\mathrm{n}} \mathrm{H}_{\mathrm{m}}$ ) are diblock molecules consisting of an ol eophobic perfluoroalkane block and an oleophilic alkane block. The mutual antipathy of the hydrocarbon and fluorocarbon chains causes a tendency to demixing of the two blocks and can lead to a selforganization of theSFA in the purestate and in solutions of hydrocarbons. Miscibility studies of hydrocarbon and fluorocarbon sol vents haveshown ${ }^{1}$ that the free energy of transfer of $\mathrm{a}-\mathrm{CH}_{2-}$ group into fluorocarbon and a $-\mathrm{CF}_{2-}$ group into hydrocarbon are approximately 1.1 and $1.4 \mathrm{~kJ}$ $\mathrm{mol}^{-1}$, respectively. Thesevalues imply that theantipathy between hydrocarbon and fluorocarbon chains is about $1 / 3$ of the free energy of transfer of $-\mathrm{CH}_{2-}$ groups from alkane to water, that is, the driving force of the hydrophobic effect. Accordingly, SFAs are expected to be relatively weak amphi philes in hydrocarbon solvents when compared with conventional surfactants of similar chain length in aqueous media. Weak aggregation of $\mathrm{F}_{n} \mathrm{H}_{m}$ molecules in hydrocarbon solvents, with aggregation numbers in the range $2-10$, was observed at concentrations abovea critical aggregation concentration (cac) which is generally much higher than the critical micelle concentration of typical surfactants in aqueous solutions. Values of the cac were determined from the temperature dependence of the solubility of the solid SFAs in the hydrocarbon solvents, which exhibits a sharp increase in a narrow temperature range, reminiscent of the Krafft point temperature of surfactants in water. ${ }^{1}$

The structure and thermal behavior of pureSFA in the bulk solid state have been studied in some detail. ${ }^{2-11} \mathrm{~F}$ or

* Corresponding author. E-mail: p.lang@fz-juelich.de

† Permanent address: Forschungszentrum J ülich, IFF, 52425 J ülich, Germany.

‡ OrganischeChemiellI U niversität UIm, 89069 UIm, Germany.

(1) Binks, B. P.; Fletcher, P. D. I.; Kotsev, S. N.; Thompson, R. L. Langmuir 1997, 13, 6669. a series of $\mathrm{F}_{\mathrm{n}} \mathrm{H}_{\mathrm{m}}$ compounds with $\mathrm{n}=12$ and $\mathrm{m}=6,8,10$, and 12 , one or more solid/solid phase transitions were found. This structural variety originates not only from the energetic incompatibility of the two blocks but also from their different cross-sectional areas. While the fluorinated block has a cross-sectional area of ca. $28 \AA^{2}$ in thesolid high-temperature phase, ${ }^{11} \mathrm{n}$-al kanes in a twodimensionally ordered surfacelayer occupy only about 20 $\AA^{2}{ }^{12} \mathrm{~F}_{\mathrm{n}} \mathrm{H}_{\mathrm{m}}$ compounds in their high-temperaturebulk solid phase are commonly arranged in monolayer lamellar stacks in which thefluorinated chains areoriented vertical to the planes in a two-dimensional (2D) hexagonal close packing, while the hydrocarbon tails are in a weakly ordered, liquidlike state with a large number of gauche defects along the chain. In this state, the contact area between the fluorinated and hydrogenated blocks of the $\mathrm{F}_{\mathrm{n}} \mathrm{H}_{\mathrm{m}}$ molecules is minimized and the packing frustration resulting from thespatial incompati bility of thetwo blocks is relaxed. ${ }^{11}$

Due to their amphiphilic character, solutions of SFA in hydrocarbon solvents exhibit a more or less pronounced

(2) Mahler, W.; Guillon, D.; Skoulios, A. Mol. Cryst. Liq. Cryst. Lett. $1985,2,111$

(3) Rabolt, J . F.; Russell, T. P.; Twieg, R. J . Macromol ecules 1984, 17, 2786.

(4) Russell, T. P.; Rabolt, J . F.; Twieg, R.J .; Siemens, R. L.; Farmer, B. L. Macromol ecules 1986, 19, 1135.

(5) Viney, C.; Russell, T. P.; Depero, L. E.; Twieg, R. J . Mol. Cryst. Liq. Cryst. 1989, 168, 63.

(6) Viney, C.; Twieg, R. J .; Russell, T. P.; Depero, L. E. Liq. Cryst. 1989, 5, 1783

(7) Viney, C.; Twieg, R.J .; Russell, T. P. Mol. Cryst. Liq. Cryst. 1990, 182B, 291.

(8) Dorset, D. L. Macromol ecules 1990, 23, 894.

(9) Höpken, J . Ph.D. Thesis, Universiteit Twente, Enschede, The Netherlands, 1991.

(10) Lermann, E. Ph.D. Thesis, Universität UIm, UIm, Germany, 1997.

(11) Marczuk, P.; Lang, P. Macromolecules 1998, 31, 9013.

(12) Ocko, B. M.; Wu, X. Z.; Sirota, E. B.; Sinha, S. K.; Gang, O.; Deutsch, M. Phys. Rev. E 1997, 55, 3164. 
surface activity. Binks et al.1,13,14 concluded from an analysis of surfacetension data that thetendency of $F_{n} H_{m}$ mol ecules to be adsorbed at the hydrocarbon/air interface increases with theanti pathy between thefluorinated chain and the hydrocarbon solvent, that is, with increasing chain length of the fluorinated block and increasing carbon number of the hydrocarbon solvent. Hayami and Findenegg ${ }^{15}$ studied thetemperaturedependence of thesurface tension of $\mathrm{F}_{12} \mathrm{H}_{16}$ solutions in hexadecane in the temperature range $15-40{ }^{\circ} \mathrm{C}$, in which no aggregation in the bulk solution occurs. (From the Krafft temperatures of $\mathrm{F}_{8} \mathrm{H}_{16}$ and $\mathrm{F}_{10} \mathrm{H}_{16}$ in hexadecane, 30 and $48{ }^{\circ} \mathrm{C}$, respectively, ${ }^{1}$ one expects that the Krafft temperature of $\mathrm{F}_{12} \mathrm{H}_{16}$ in hexadecane is $60^{\circ} \mathrm{C}$ or greater.) Sharp breaks in the temperature derivative of the surface tension were observed, which were attributed to first-order phase transitions in the adsorbed film of $\mathrm{F}_{12} \mathrm{H}_{16}$. This study indicated striking similarities in the phase behavior between Gibbs films of $\mathrm{F}_{\mathrm{n}} \mathrm{H}_{\mathrm{m}}$ at the hydrocarbon/air interface and Gibbs films of fatty alcohols and related amphiphiles at the water/air ${ }^{16}$ and water/oi ${ }^{17}$ interfaces. In the system $\mathrm{F}_{12} \mathrm{H}_{16}+$ hexadecane, a complication arises from the fact that hexadecane exhibits the phenomenon of surface freezing a few Kelvin above the bulk freezing temperature. ${ }^{12}$ It was found that the phase transition of the Gibbs film of $\mathrm{F}_{12} \mathrm{H}_{16}$ competes with thesurfacefreezing of the pure hexadecane solvent. ${ }^{15}$ Also, a pronounced correlation of molecular orientations exists in the liquid state of higher $n$-alkanes such as hexadecane ${ }^{18}$ at temperatures near their freezing points. Hence, it was of interest to study the influence of such correlations of molecular orientations of the hydrocarbon solvent on the structure and thermodynami cstability of the Gibbs films of $\mathrm{F}_{\mathrm{n}} \mathrm{H}_{\mathrm{m}}$ amphiphiles. Such effects can be revealed by comparing the properties of Gibbs films on n-alkanes of different chain length as well as branched or cyclic hydrocarbon solvents. It was also of interest to see how the chain length of the hydrocarbon tail of the $\mathrm{F}_{\mathrm{n}} \mathrm{H}_{\mathrm{m}}$ molecules affects the properties of the Gibbs films in different hydrocarbon solvents.

In this work, we study Gibbs films of a series of $\mathrm{F}_{12} \mathrm{H}_{\mathrm{m}}$ compounds ( $m=12,14,16$, and 18) at the surface of solutions in three hydrocarbons, n-dodecane and bicyclohexyl ( $\mathrm{H}_{12}$ solvents) and $\mathrm{n}$-hexadecane ( $\mathrm{H}_{16}$ solvent). The experimental temperature range $\left(10-30^{\circ} \mathrm{C}\right)$ is bel ow the estimated Krafft temperature of all these systems, where no aggregation of the SFA in the bulk solution occurs. In addition to surfacetension measurements, two complementary surface-sensitive scattering techniques, $X$-ray reflectometry $(X R)$ and grazing incidence $X$-ray diffraction (GIXD), areemployed. ${ }^{19-21}$ In XR, onemeasures the specular reflectivity of X-rays as a function of the

(13) Binks, B. P.; Fletcher, P. D. I.; Sager, W. F. C.; Thompson, R. L. Langmuir 1995, 11, 977.

(14) Binks, B. P.; Fletcher, P. D. I.; Thompson, R. L. Ber. BunsenGes. Phys. Chem. 1996, 100, 232.

(15) Hayami, Y.; Findenegg, G. H. Langmuir 1997, 13, 4865

(16) Motomura, K.; I wanaga, S.; Hayami, Y.; U ryu, S.; Matuura, R. J . Colloid Interface Ści. 1981, 80, 32. Aratono, M.; Uryu, S.; Hayami, Y.; Motomura, K.; Matuura, R. J. Colloid Interface Sci. 1984, 98, 33. (17) Hayami, Y.; Uemura, A.; I keda, N.; Aratono, M.; Motomura, K. J. Colloid Interface Sci. 1995, 172, 142. Takiue, T.; Yanata, A.; I keda, N.; Hayami, Y.; Motomura, K.; Aratono, M. J . Phys. Chem. 1996, 100, 20122.

(18) Bothorel, P.; Such, C.; Clément, C. J . Chim. Phys. 1972, 69, 1453.

(19) Als-Nielsen, J .; J acquemain, D.; Kjaer, K.; Leveiller, F.; Lahav,

M.; Leiserowitz, L. Phys. Rep. 1994, 246, 251.

(20) Kjaer, C. Physica B 1994, 198, 100.

(21) Lang, P. In Modern Characterization Methods of Surfactant Systems; Binks, B. P., Ed.; Surfactant Science Series Vol. 83; Marcel Dekker: New York, 1999. scattering vector $q_{z}$ normal to thesurface. The reflectivity $R\left(q_{z}\right)$ is related to the electron density profile in the direction normal to the surface $\rho_{\mathrm{e}}(\mathrm{z})$. The most commonly used method for the determination of electron density profiles from reflectivity curves is the so-called multibox (or slab) model ${ }^{19}$ in which the profiles are analyzed in terms of box height, box density, and the roughness parameter of theinterface between adjacent boxes. In the present case, attemptstofit experimental data with curves calculated from a two-box model often yiel ded roughness parameters which were as large as $30-50 \%$ of the height of the neighboring boxes. We therefore applied mainly the model-independent groove tracking method within Parratt's formalism²2,23 which was combined with the simulated annealing technique ${ }^{24}$ to avoid local minima.

In GIXD experiments, theangl eof incidence of theX-ray beam is bel ow thecritical angle of total external reflection. In this case, the transmitted beam degenerates to an evanescent wave which propagates al ong thesurface and is sensitive only to structures within a thin layer close to the sample surface. The scattered intensity is mapped as a function of thescattering vector $q_{x y}$ parallel tothesurface and $\mathrm{q}_{\mathrm{z}}$ perpendi cular to the surface. We have adopted the routines devel oped for the analysis of GIXD experiments on Langmuir monolayers, ${ }^{20}$ where the surface molecules are regarded as cylindrical bodies with their centers of mass arranged in arrays with 2D hexagonal or centered rectangular unit cells. Such ordered surface structures cause Bragg reflexes (rods). The scattered intensity as a function of $q_{x y}$ is related to positional correlations in the surface plane, and theintensity as a function of $q_{z}$ allows the determination of the tilt directions and tilt angles of the cylinders.

The paper is organized as follows. First, we present surfacetension measurements on Gibbs films of $\mathrm{F}_{12} \mathrm{H}_{18}$ in dodecane and an analysis of the data in terms of the adsorption isotherms and surfacephase transition. In the main part of the paper, we report XR and GIXD measure ments for Gibbs films of a series of $\mathrm{F}_{12} \mathrm{H}_{\mathrm{m}}$ materials at the surface of their solutions in dodecane and bicyclohexyl $(\mathrm{BCH})$ and of $\mathrm{F}_{12} \mathrm{H}_{16}$ on hexadecane. Preliminary results for SFA films on dodecane have been presented elsewhere. ${ }^{25}$ The data are analyzed in terms of the thickness and packing density of the Gibbs films at temperatures above and below the surface phase transition. In the Discussion, we elaborate on the peculiarities of these systems and possible reasons for theanomal ous behavior of the $\mathrm{F}_{12} \mathrm{H}_{16} /$ hexadecane system, and we compare the behavior of the present Gibbs films adsorbed from dilute solutions with recent results of the surface structure of pureSFA materialsat temperatures just abovethemelting point. 26

\section{Experimental Section}

Materials. The perfluoroal kylalkanes $\mathrm{F}_{12} \mathrm{H}_{12}, \mathrm{~F}_{12} \mathrm{H}_{14}, \mathrm{~F}_{12} \mathrm{H}_{16}$ and $\mathrm{F}_{12} \mathrm{H}_{18}$ were synthesized and purified foll owing the method of Mahler and of Höpken et al.2,9,27 The solvents $\mathrm{n}$-dodecane, n-hexadecane, and bicyclohexyl were received from F luka with a purity greater than $98 \%$ and used without further purification.

Surface Tension.Surfacetension measurements weremade under atmospheric pressure by the pendant drop technique as

(22) Zhou, X.-L.; Chen, S.-H. Phys. Rev. E 1993, 47, 3174.

(23) Parratt, L. G. Phys. Rev. 1954, 95, 359.

(24) Kirkpatrick, S.; Gelatt, C. O.; Vecchi, M. P. Science 1983, 220, 671.

(25) Marczuk, P.; Lang, P.; Möller, M. Colloids Surf., A 2000, 163, 103.

(26) Gang, O.; Ellmann, J .; Möller, M.; Kraack, H.; Sirota, E. B.; Ocko, B. M.; Deutsch, M. Europhys. Lett. 2000, 49, 761.

(27) Höpken, J.; Pugh, C.; Richtering, W.; Möller, M. Makromol Chem. 1990, 189, 911. 
reported previously. ${ }^{15}$ Drops of ca. $3 \mathrm{~mm}$ equatorial diameter were suspended from a glass rod in a closed glass cell with optically flat windows. SFA sol utions were prepared by weight. Some excess amount of the solution was kept at the bottom of the cell, to saturate the vapor space with the solvent and thus to minimize its evaporation from the drop during the measure ments. Drop shape measurements on drops of given SFA concentrations weremadeat a series of temperatures by lowering temperature in discrete steps with an equilibration time of at least 30 min at each experimental temperature. Thetemperature of the cell was controlled to within $\pm 0.01 \mathrm{~K}$. The drop contour was imaged by means of a CCD camera, and the surface tension was calculated from the drop shape by the selected plane method. ${ }^{28}$ At least 300 images were analyzed and averaged for each data point. The statistical error resulting from these repeated measurements was $\pm 0.05 \mathrm{mN} / \mathrm{m}$, whilethe systematic error due to calibration and other artifacts is estimated as \pm 0.5 $\mathrm{mN} / \mathrm{m}$ from a comparison of calibration measurements with several pure liquids with literature data.

X-ray Reflectometry. Measurements were made using a home-built reflectometer, specially designed for reflectivity measurements from the air/liquid interface. The instrument is equipped with a standard Cu tube as the X-ray source and was operated at $40 \mathrm{kV}$ and $35 \mathrm{~mA}$. A collimating Göbel mirror 29 (Bruker AXS, Karlsruhe, Germany) was used as the monochromator to select the $\mathrm{K} \alpha$ wavelength $\lambda=1.54 \AA$. A metal wire position-sensitive detector OED-50M (MBraun, München, Germany) was used to detect the scattered photons. The resolution of the detector was calibrated with a silver behenate powder sample. ${ }^{30}$ The collimating system consists of two horizontal slits between the monochromator and the sample. The X-ray tube, both slits, and the detector are mounted on X-95 profiles, which areconnected by a swivel joint and can beinclined independently by means of two vertical stages (type 5101, Huber Diffraktionstechnik, Rimstig, Germany). For the measurements, SFA solutions were poured onto a clean sandblasted steel plate of a covered and sealed steel cell. The temperature of the socket and the cover of the cell was controlled with an accuracy of $\pm 5 \mathrm{mK}$ by a Haake $\mathrm{F} 6$ bath thermostat (Haake, Karlsruhe, Germany) and monitored by a standard Pt-100 resistor. During temperature scans (reflectivity measurements at a constant incident angle), the temperature was varied in 100 steps per hour with a step width of $0.01 \mathrm{~K}$.

Grazing Incidence X-ray Diffraction. GIXD experiments were conducted at the beamlines D4.1 and BW1 of the HASYLAB at DESY in Hamburg, Germany. The general setup of both instruments is described el sewhere. ${ }^{19,31} \mathrm{~F}$ or our measurements, we used a wavelength of $\lambda=1.3037 \AA$ and a Soller collimator, which sets the angular resolution in the surface $\left(q_{x y}\right)$ plane to $\Delta(2 \theta)=0.15^{\circ}$. The sample environment was modified by placing the socket of the sample cell with the temperature controlling and monitoring system into a closed container with large capton windows for theincident and thescattered radiation. Toimprove the signal-to-noise ratio, the canister was flushed with solventsaturated helium at the respective experimental temperature.

\section{Results}

Surface Tension Data. Figure 1 shows the temperature dependence of the surface tension $\gamma$ of $\mathrm{F}_{12} \mathrm{H}_{18}$ solutions in dodecane for concentrations up to $3 \mathrm{mmol} / \mathrm{kg}$. In dilutesol utions (up to $0.6 \mathrm{mmol} / \mathrm{kg}$ ), thesurfacetension exhibits a weak ly negative temperature dependence over the entire experimental range. In more concentrated solutions $(0.9 \mathrm{mmol} / \mathrm{kg}$ and greater $)$, one observes a sharp transition from this $\mathrm{d} \gamma / \mathrm{dT}<0$ behavior at high temperatures toa region with a positivesl opeat low temperatures.

(28) Andreas, J .; Hauser, E.; Tucker, W. J . Phys. Chem. 1938, 42, 1001.

(29) Bergmann, A.; Orthaber, D.; Scherf, G.; Glatter, O. J . Appl Crystallogr. 2000, 33, 869.

(30) Huang, T. C.; Toraya, H.; Blanton, T. N.; Wu, Y. J . J . Appl. Crystallogr. 1993, 26, 180.

(31) Kjaer, C. Experimental Stations at HASYLAB; Risø National Laboratory: Roskilde, Denmark, 1994; p 88.

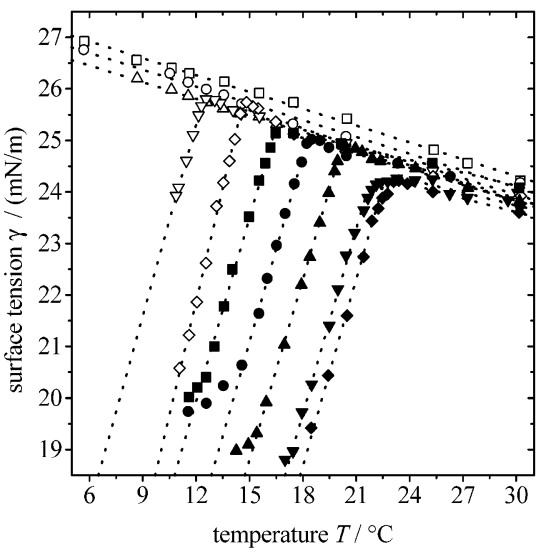

Figure 1. Surface tension $\gamma$ as a function of temperature for solutions of $\mathrm{F}_{12} \mathrm{H}_{18}$ on dodecane. The symbols represent experimental data for different solute concentrations $(O$, pure solvent; $\triangle, 0.30 \mathrm{mmol} / \mathrm{kg}$; $\square, 0.60 \mathrm{mmol} / \mathrm{kg} ; \nabla, 0.90 \mathrm{mmol} / \mathrm{kg}$; $\diamond, 1.16 \mathrm{mmol} / \mathrm{kg} ; \mathbf{\square}, 1.43 \mathrm{mmol} / \mathrm{kg} ; \bullet, 1.77 \mathrm{mmol} / \mathrm{kg} ; \Delta, 2.19$ $\mathrm{mmol} / \mathrm{kg} ; \nabla, 2.70 \mathrm{mmol} / \mathrm{kg} ; \diamond, 3.00 \mathrm{mmol} / \mathrm{kg}$ ), and the dotted lines are linear least-squares fits to the branches with negative and positive slopes of the respective data set.

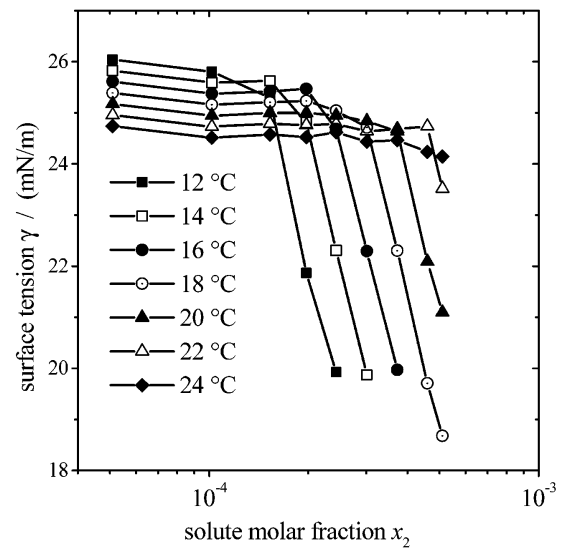

Figure 2. Surface tension $\gamma$ as a function of the solute mole fraction $x_{2}$ at constant temperatures, as indicated in thelegend.

The transition temperature $\mathrm{T}_{\mathrm{f}}$ separating these two regimes increases with increasing concentration of $\mathrm{F}_{12} \mathrm{H}_{18}$. In the high-temperature region, $\gamma$ is a linear function of temperature, and increasing the concentration at constant temperature causes a weak decrease of $\gamma$, indicating a weak adsorption of SFA at the free surface of dodecane. Below the phase transition, $\gamma$ is also a linear function of T but deviations from this linear temperaturedependence occur at low temperatures, presumably due to incomplete dissolution of theSFA near its solubility limit in dodecane. Only the data in the linear region, which are not affected by this artifact, were used in the data analysis. As shown by vapor pressure osmometry by Binks et al. ${ }^{13}$ for two related systems, the SFA solutions behave ideally up to the solubility limit.

Accordingly, the relative surface excess concentration of the solute, $\Gamma_{2}{ }^{(1)}$, was derived using the Gibbs equation without correction for nonideality ${ }^{13,15}$

$$
\Gamma_{2}^{(1)}=-\frac{1}{\mathrm{RT}}\left(\frac{\partial \gamma}{\partial \ln x_{2}}\right)
$$

Figure 2 shows graphs of surface tension versus mole fraction $x_{2}$ on a semilogarithmic scale. In this representation, the isotherms show two regions of constant slope $\partial \gamma / \partial \ln \mathbf{x}_{2}$, and both slopes are essential ly independent of temperature. Thesefindings imply that thesurfaceexcess 


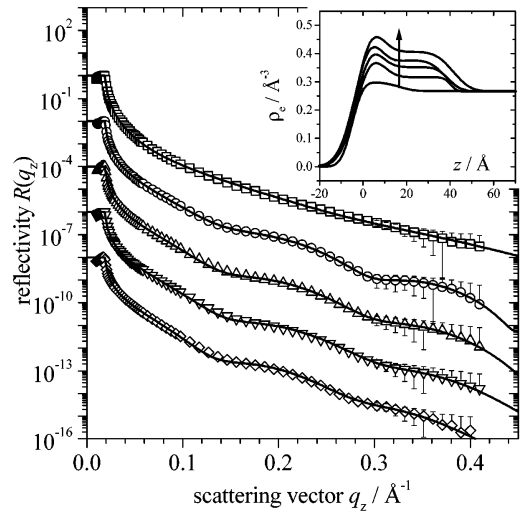

Figure 3. X-ray reflectivity $\mathrm{R}\left(\mathrm{q}_{z}\right)$ versus scattering vector $\mathrm{q}_{z}$ from the surface of a solution of $2.184 \mathrm{mmol} / \mathrm{kg} \mathrm{F}_{12} \mathrm{H}_{16}$ in hexadecane above $T_{f}(\square)$ and at four different temperatures below $\mathrm{T}_{\mathrm{f}}$ : $O, 22.3^{\circ} \mathrm{C} ; \triangle, 20.0^{\circ} \mathrm{C} ; \nabla, 19.3^{\circ} \mathrm{C} ; \diamond, 17.6^{\circ} \mathrm{C}$. Symbols are experimental data, and the full lines represent best fits obtained from a two-box model of the electron density profile normal tothesurface $\rho_{\mathrm{e}}(\mathrm{z})$. The corresponding electron density distributions are shown in the inset; the arrow indicates the direction of decreasing temperature.

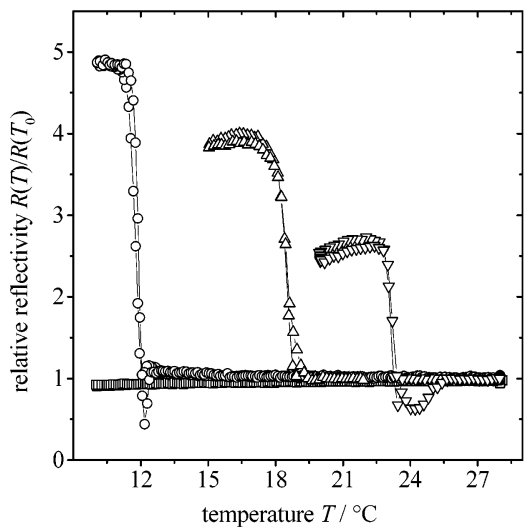

Figure 4. Relative reflectivity $R(T) / R\left(T_{0}\right)$ from the surface of solutions of $3.0 \mathrm{mmol} / \mathrm{kg} \mathrm{SFA}$ in dodecane as a function of temperature at constant $\mathrm{q}_{\mathrm{z}}=0.1 \AA^{-1}: \square, \mathrm{F}_{12} \mathrm{H}_{12} ; \mathrm{O}, \mathrm{F}_{12} \mathrm{H}_{14} ; \Delta$, $\mathrm{F}_{12} \mathrm{H}_{16} ; \nabla, \mathrm{F}_{12} \mathrm{H}_{18}$.

concentration exhibits a transition from a low value $\left(\Gamma_{2}{ }^{(1)}\right.$ $\left.=0.11 \pm 0.07 \mu \mathrm{mol} / \mathrm{m}^{2}\right)$ to a high value $\left(\Gamma_{2}{ }^{(1)}=4.8 \pm 0.3\right.$ $\mu \mathrm{mol} / \mathrm{m}^{2}$ ) as the bulk concentration is increased. On the assumption that $\Gamma_{2}{ }^{(1)}$ can be identified with the absolute surface concentration, the latter value corresponds to a mean area per molecule of $34 \pm 2 \AA^{2}$, which is about $20 \%$ greater than for a close-packed ordered monolayer of perfluoroalkyl chains $\left(28 \AA^{2}\right) .{ }^{11}$

X-ray R eflectivities. XR curves $R\left(q_{z}\right)$ of thesurface of SFA solutions in different hydrocarbon solvents were recorded at temperatures below and above the phase transition temperature $T_{f}$ of the Gibbs film. A representative example is shown in Figure 3.

Above $T_{f}$, the $X R$ curves exhibit a monotonic decay of $R\left(q_{z}\right)$ at $q_{z}>q_{c}$ (critical value of total external reflection), as expected for the free surface of simple liquids. The existence of a dense Gibbs film at temperatures bel ow $T_{f}$ is indicated by a modulation of this simple decay. The transition from the high-temperature state to the lowtemperaturestate of thefilm was monitored by recording the temperature dependence of the reflectivity at some fixed value of $q_{z}$ at which $R\left(q_{z}\right)$ of the low-temperature phase deviates markedly from that of the high-temperature phase. Figure 4 shows results of such a temperature scan recorded at $q_{z}=0.1 \AA^{-1}$ for solutions of the four

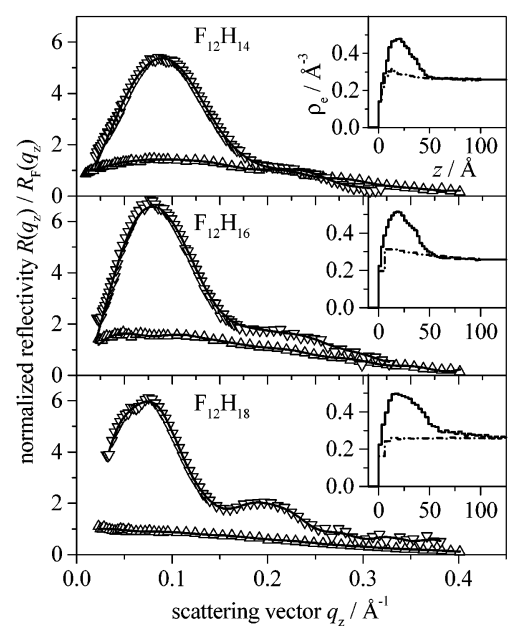

Figure 5. Reflectivity normalized to the Fresnel reflectivity of an ideal (hypothetical) pure solvent surface $R\left(q_{z}\right) / R_{F}\left(q_{z}\right)$ vs scattering vector $q_{z}$ from the surface of three solutions of 3 $\mathrm{mmol} / \mathrm{kg} \mathrm{F}_{12} \mathrm{H}_{\mathrm{m}}$ in dodecane. The data were col lected $3 \mathrm{~K}$ above $(\triangle)$ and $3 \mathrm{~K}$ below $(\nabla) \mathrm{T}_{\mathrm{f}}$. The solid lines are best fits according totheel ectron density profiles displayed in theinsets (full lines, low temperature; dotted lines, high temperature).

$\mathrm{F}_{12} \mathrm{H}_{\mathrm{m}}$ materials in dodecane at a sol ute concentration of ca. $3 \mathrm{mmol} / \mathrm{kg}^{25}$

For a better comparison of the four systems, the reflectivities are plotted as $R(T) / R\left(T_{0}\right)$, where $R\left(T_{0}\right)$ is the reflectivity of the respective system at a reference temperatureabovethephasetransition. For thesamples with $\mathrm{m}=14,16$, and 18 , the XR scans exhibit a sharp step in the experimental temperature window. The phase transition temperature $T_{f}$ determined from the position of this step is reproducible, and no significant hysteresis is observed in cooling-heating cycles (Figure4). As expected, $\mathrm{T}_{\mathrm{f}}$ increases with thechain length of the hydrocarbon tail, suggesting that a similar phase transition will occur for $\mathrm{F}_{12} \mathrm{H}_{12}$ at a lower temperature.

Full XR curves of the $\mathrm{F}_{12} \mathrm{H}_{\mathrm{m}}+$ dodecane systems $(\mathrm{m}=$ 14,16 , and 18 ) recorded at temperatures ca. $3 \mathrm{~K}$ above and $3 \mathrm{~K}$ below the respective transition temperature $T_{f}$ are shown in Figure $5 .{ }^{25}$ In this figure, $R\left(q_{z}\right)$ is normalized to the Fresnel reflectivity $R_{F}\left(q_{z}\right)$ of an idealized surface with a step-function profile $\rho_{\mathrm{e}}(\mathrm{z})$ changing at $\mathrm{z}=0$ from zero (gas phase) to the el ectron density of bulk dodecane. At temperatures $T>T_{f}$, thenormalized reflectivity curves $R\left(q_{z}\right) / R_{F}\left(q_{z}\right)$ arenearly featurel ess as expected for a simple surface without adsorbed film. The respective curves for the low-temperature phase $\left(T<T_{f}\right)$ exhibit a pronounced primary maximum and a weaker secondary maximum, which becomes more prominent as the chain length of the hydrocarbon tail increases. The reflectivity data were analyzed in terms of the electron density profile $\rho_{\mathrm{e}}(\mathrm{z})$ on thebasis of thefirst Born approximation. For an air/liquid interface,

$$
\frac{\mathrm{R}\left(\mathrm{q}_{\mathrm{z}}\right)}{\mathrm{R}_{\mathrm{F}}\left(\mathrm{q}_{\mathrm{z}}\right)}=\frac{1}{\rho_{\infty}^{2}} \mid \int_{-\infty}^{\infty} \frac{\mathrm{d} \rho_{\mathrm{e}}(\mathrm{z})}{\mathrm{dz}} \exp \left\{\left.\mathrm{iq} \mathrm{z} z \mathrm{dz}\right|^{2}\right.
$$

where $\mathrm{d} \rho_{\mathrm{e}}(\mathrm{z}) / \mathrm{d} z$ is the el ectron density gradient averaged over the $x-y$ plane, and $\rho_{\infty}$ is the el ectron density in the bulk liquid phase. The density profiles derived from the model-independent analysis of the reflectivity are shown in theinset of Figure5. Thehigh-temperaturereflectivity data $\left(T>T_{f}\right)$ of the $F_{12} \mathrm{H}_{18}$ system yield an al most steplike density profilerising from effectively zero (at $z \leq 0)$ to the electron density of the liquid bulk phase $\left(\rho_{\infty}=0.26 \AA^{-3}\right.$ 
Table 1. Relative Packing Density $\Theta$ of $\mathrm{F}_{12} \mathrm{H}_{\mathrm{m}}$ on Dodecane and $\mathrm{BCH}^{\mathrm{a}}$

\begin{tabular}{lcccc}
\hline \multicolumn{1}{c}{$\mathrm{m}$} & $\mathrm{t} / \AA$ & $\mathrm{C} * / \AA^{2}$ & $\mathrm{C} / \AA^{2}$ & $\Theta=\mathrm{C} / \mathrm{C}^{*}$ \\
\hline 14 & 13.58 & 7.53 & 6.2 & 0.82 \\
16 & 15.37 & 7.62 & 7.1 & 0.93 \\
18 & 17.16 & 7.71 & 7.7 & 1.0 \\
$16(\mathrm{BCH})$ & 15.37 & 6.34 & 7.6 & 1.2 \\
$18(\mathrm{BCH})$ & 17.16 & 6.37 & 8.2 & 1.29
\end{tabular}

a $t$ is the overall thickness of a hypothetical layer of solidlike alkane as explained in the main text. $C$ and $C^{*}$ are given by eqs 3 and 4 . To calculate $C^{*}$, we used the el ectron density of the pure $\mathrm{H}_{12}$ solvents, i.e., $\rho_{\mathrm{H}, \mathrm{I}}=0.26 \AA^{-3}$ for dodecane and $\rho_{\mathrm{H}, \mathrm{I}}=0.30 \AA^{-3}$ for $\mathrm{BCH}$. The uncertainties in $\mathrm{C}$ and $\Theta$ are less than \pm 1 in the last digit.

at $z \geq 0$ ). $F$ or $F_{12} \mathrm{H}_{16}$ and $\mathrm{F}_{12} \mathrm{H}_{14}$ at $\mathrm{T}>\mathrm{T}_{\mathrm{f}}$, the density profiles exhibit a weak maximum next to the surface, indicating some adsorption of these semi-fluorinated alkanes. For temperatures $T<T_{f}$, density profiles with a pronounced maximum, amounting to an el ectron density $\rho_{\max } \approx 0.5 \AA^{-3}$, are obtained. This value of $\rho_{\max }$ agrees with the value $\left(\approx 0.52 \AA^{-3}\right)$ calculated from the effective molecular area as deduced from surface tension data. However, the region of excess el ectron density $\left(\rho_{\mathrm{e}}(\mathrm{z})>\rho_{\infty}\right)$ extends to a depth of ca. $50 \AA$ for $\mathrm{F}_{12} \mathrm{H}_{14}$ and $\mathrm{F}_{12} \mathrm{H}_{16}$. For $\mathrm{F}_{12} \mathrm{H}_{18}$, there is a further region of slowly decaying excess density that extends to nearly $100 \AA$ in depth. The integrated surface excess electron density has been evaluated as

$$
C=\int_{0}^{\infty} \rho_{\mathrm{e}}(\mathrm{z})-\rho_{\mathrm{e}}^{0}(\mathrm{z}) \mathrm{dz}
$$

where $\rho_{\mathrm{e}}(\mathrm{z})$ and $\rho_{\mathrm{e}} \mathrm{O}(\mathrm{z})$ are the electron density profiles as derived from the refl ectivity data of the solution and pure dodecanesolvent, respectively. I n this relation, weneglect the small difference in the electron density of the dilute solutions and the pure solvent. In Table 1, the values of $C$ derived from the experimental data on the basis of eq 3 are compared with the reference value (denoted $C^{*}$ ) for a monolayer of the respective $\mathrm{F}_{12} \mathrm{H}_{\mathrm{m}}$ in which both the fluorinated and thehydrogenated blocks areclose packed. Sincethe cross-sectional area of a hydrocarbon chain $\left(A_{H}\right)$ is less than the cross-sectional area of the fluorocarbon chain $\left(A_{F}\right)$, close packing of both the fluorocarbon and hydrocarbon chains of the SFA molecules implies a tilt of the hydrocarbon chains with respect to the longitudinal direction of the fluorinated chains, with a tilt angle $\phi=$ $\arccos \left(\mathrm{A}_{\mathrm{H}} / \mathrm{A}_{\mathrm{F}}\right) \approx 45^{\circ}$.

$$
C^{*}=\rho_{\mathrm{F}} \mathrm{I}_{\mathrm{F}}+\rho_{\mathrm{H}, \mathrm{C}} \mathrm{t}-\rho_{\mathrm{H}, \mathrm{I}}\left(\mathrm{I}_{\mathrm{F}}+\mathrm{t}\right)
$$

where $\rho_{\mathrm{F}}, \rho_{\mathrm{H}, \mathrm{C}}$, and $\rho_{\mathrm{H}, \mathrm{I}}$ are the electron densities of closepacked fluorocarbon and alkane layers $\left(\rho_{\mathrm{F}}=0.67 \AA^{-3,32}\right.$ $\rho_{\mathrm{H}, \mathrm{C}}=0.32 \AA^{-312}$ ) and of the liquid hydrocarbon solvent $\left(\rho_{\mathrm{H}, \mathrm{I}}=0.26 \AA^{-3}\right.$ for dodecane, $\rho_{\mathrm{H}, \mathrm{l}}=0.30 \AA^{-3}$ for bicyclohxyl, and $\rho_{H, I}=0.27 \AA^{-3}$ for hexadecane); $I_{F}=16.7 \AA$ is the length of the extended $F_{12}$ chain; 33 and $t=I_{H} \cos \phi$ the thickness of the tilted layer of hydrocarbon tails of length $I_{H}=(1.265 m+1.5) \AA$. Values of $C^{*}$ and the quantity $\Theta$ $=\mathrm{C} / \mathrm{C}^{*}$, the relative packing density expressed in terms of a close-packed monolayer of $\mathrm{F}_{12} \mathrm{H}_{\mathrm{m}}$, are given in Table 1. For the Gibbs films of the three $\mathrm{F}_{12} \mathrm{H}_{\mathrm{m}}$ compounds on dodecane, at a temperature $3 \mathrm{~K}$ bel ow therespectivephase transition, $\Theta$ values increasing from $0.82\left(\mathrm{~F}_{12} \mathrm{H}_{14}\right)$ to 0.99 $\left(\mathrm{F}_{12} \mathrm{H}_{18}\right)$ are found.

(32) Bunn, W. C.; Howell, E. R. Nature 1954, 174, 549.

(33) Birshtein, T. M.; Ptitsyn, O. B. Conformations of Macromol ecules; J ohn Wiley \& Sons: New York, 1966.

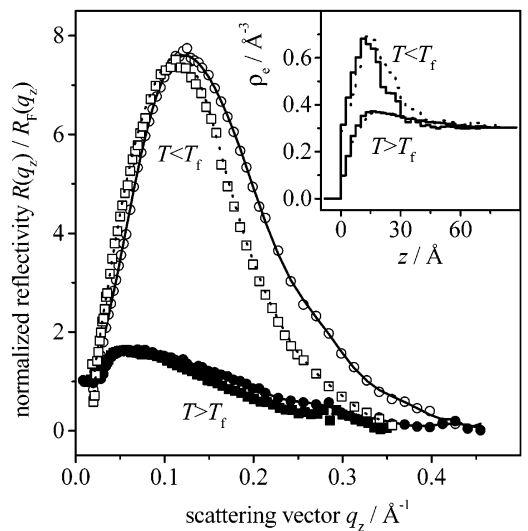

Figure 6. Reflectivity normalized to the F resnel reflectivity of the pure solvent surface $R\left(q_{z}\right) / R_{F}\left(q_{z}\right)$ vs scattering vector $q_{z}$ from the surface of two solutions of $1 \mathrm{mmol} / \mathrm{kg} \mathrm{F}_{12} \mathrm{H}_{\mathrm{m}}$ in bicycl ohexyl. Symbol s are experimental points: $\mathrm{F}_{12} \mathrm{H}_{16}(\mathrm{O})$ and $\mathrm{F}_{12} \mathrm{H}_{18}(\square) 3 \mathrm{~K}$ below $\mathrm{T}_{f} ; \mathrm{F}_{12} \mathrm{H}_{16}(\bullet)$ and $\mathrm{F}_{12} \mathrm{H}_{18}(\boldsymbol{\square}) 3 \mathrm{~K}$ above $\mathrm{T}_{\mathrm{f}}$. The lines are best fits according to the electron density profiles displayed in the inset $\left(\mathrm{F}_{12} \mathrm{H}_{16}\right.$, full lines; $\mathrm{F}_{12} \mathrm{H}_{18}$, dotted lines).

$X R$ measurements on $F_{12} \mathrm{H}_{m}$ solutions in the bulky hydrocarbon $\mathrm{BCH}$ were made to study the influence of the hydrocarbon solvent on the properties of the Gibbs films. Sincethe sol ubility of the semi-fluorinated alkanes in $\mathrm{BCH}$ is less than in dodecane, solutions of $1 \mathrm{mmol} / \mathrm{kg}$ were used in these measurements. Figure 6 shows $\mathrm{R}\left(\mathrm{q}_{z}\right) /$ $\mathrm{R}_{\mathrm{F}}\left(\mathrm{q}_{\mathrm{Z}}\right)$ curves for $\mathrm{F}_{12} \mathrm{H}_{16}$ and $\mathrm{F}_{12} \mathrm{H}_{18}$ on $\mathrm{BCH}$ recorded at temperatures $3 \mathrm{~K}$ below and $3 \mathrm{~K}$ above the respective phase transition temperature $T_{f}$. The el ectron density profiles $\rho_{\mathrm{e}}(\mathrm{z})$ were again derived from the normalized reflectivities $R\left(q_{z}\right) / R_{F}\left(q_{z}\right)$ by the model-independent analysis and are shown as an inset in Figure 6. At $T>T_{f}$, the profiles of the two systems coincide within experimental accuracy and exhibit a very weak maximum near $z=0$, again indicating someadsorption of the ${ }_{12} \mathrm{H}_{\mathrm{m}}$ compounds at thesurface of theliquid phase. The profiles do not exhibit a sharp step at $z=0$ as in the dodecane systems but increasemoregradually over a range of ca. $12 \AA$, indicating a higher surface roughness than in the case of dodecane. Fromtheelectron density profiles for thelow-temperature phase $\left(T<T_{f}\right.$ ) of $F_{12} \mathrm{H}_{16}$ and $\mathrm{F}_{12} \mathrm{H}_{18}$, it follows that the Gibbs films on $\mathrm{BCH}$ are more compact than on dodecane.

Specifically, the peak value of the electron density is significantly higher $\left(\rho_{\max } \approx 0.65 \AA^{-3}\right)$ than in therespective dodecane systems, and the thickness of the region with excess electron density is significantly smaller. This is duetothe fact that theel ectron density difference between the hydrocarbon part of the condensed film $\left(\rho_{\mathrm{H}_{\mathrm{C}}}=0.32\right.$ $\left.\AA^{-3}\right)$ and the solvent $\left(\rho_{\mathrm{H}, \mathrm{l}}=0.30 \AA^{-3}\right)$ is much smaller than in the dodecane systems. On the other hand, the peak value of the profiles is very close to that of a hypothetical perfectly ordered $\mathrm{F}_{12}$ layer, indicating a very high packing density in the film. This is al so brought out by the values of $\Theta=C / C^{*}$ in Table 1, which are larger than unity. Considering the simplicity of the applied model, this is clear evidence for a complete surface coverage by the solute.

Gibbs films of $\mathrm{F}_{12} \mathrm{H}_{16}$ on hexadecane were studied to assess the effect of the correlation of molecular orientations in the liquid state $\mathrm{e}^{18}$ on the properties of the Gibbs films. Figure 7 shows a temperaturescan of thereflectivity $R(T) /$ $\mathrm{R}\left(\mathrm{T}_{0}\right)$ recorded at $\mathrm{q}_{\mathrm{z}}=0.2 \AA^{-1}$ for a solution of $2.2 \mathrm{mmol} / \mathrm{kg}$ $\mathrm{F}_{12} \mathrm{H}_{16}$ in hexadecane. Clearly, this system exhi bits not a sharp phase transition but a gradual increase of the reflectivity over a range of several Kelvin, starting at $T_{f}$ $\approx 23.5^{\circ} \mathrm{C}$, where $\mathrm{T}_{\mathrm{f}}$ now represents theonset temperature of the surface phase transition. On further cooling, the 

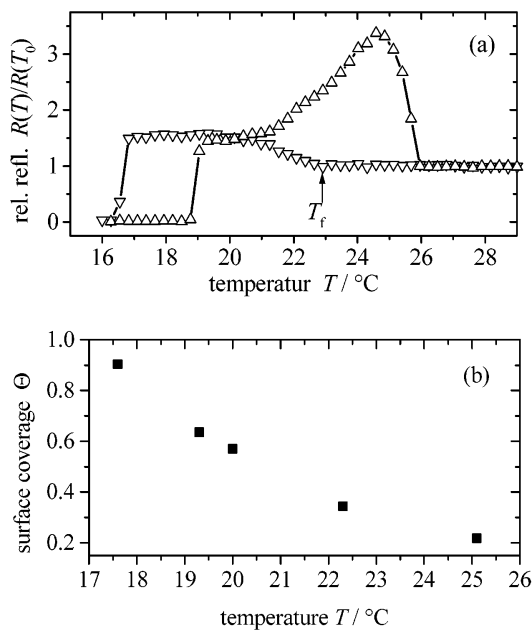

Figure 7. (a) Relative reflectivity $R(T) / R\left(T_{0}\right)$ at $q_{z}=0.2 \AA^{-1}$ from the surface of a solution of $2.184 \mathrm{mmol} / \mathrm{kg} \mathrm{F}_{12} \mathrm{H}_{16}$ in hexadecane in dependence of temperature $(\Delta$, heating; $\nabla$, cooling). Theapplied cooling/heating ratewas $1 \mathrm{~K} / \mathrm{h}$. (b) Relative packing density $\Theta$ at selected temperatures. $\Theta$ was calculated on the basis of eqs 3 and 4 from the el ectron density profiles displayed in Figure 8b.

value of $R(T) / R\left(T_{0}\right)$ recorded at $q_{z}=0.2 \AA^{-1}$ remains nearly constant and then falls off shar ply to nearly zero at ca. 17 ${ }^{\circ} \mathrm{C}$, when the bulk sample freezes. The heating curve of $\mathrm{R}(\mathrm{T}) / \mathrm{R}\left(\mathrm{T}_{0}\right)$ scans, when measured at a similar scanning rateas thecooling curve (ca. $1 \mathrm{~K} / \mathrm{min})$, is displaced upward by typically $2-3 \mathrm{~K}$ and exhibits a pronounced maximum near $25^{\circ} \mathrm{C}$, that is, ca. $2 \mathrm{~K}$ above $\mathrm{T}_{\mathrm{f}}$. This observation indicates that in this system the equilibration is quite slow in the temperature range of the surface phase transition.

Full $R\left(q_{z}\right)$ curves of a $2.2 \mathrm{mmol} / \mathrm{kg}$ sample of $\mathrm{F}_{12} \mathrm{H}_{16}$ in hexadecane are given in Figure 3 . The corresponding normalized reflectivities $\mathrm{R}\left(\mathrm{q}_{\mathrm{z}}\right) / \mathrm{R}_{\mathrm{F}}\left(\mathrm{q}_{\mathrm{z}}\right)$ are shown in Figure 8. The curve for $25.1{ }^{\circ} \mathrm{C}$ corresponds to the gaslike state above $\mathrm{T}_{\mathrm{f}}$, those for $22.3,20.0$, and $19.3^{\circ} \mathrm{C}$ to the region assigned as the liquid expanded state in ref 15 , and that for $17.6^{\circ} \mathrm{C}$ to the liquid condensed state of the Gibbs film just beforebulk freezing. All curves for temperatures below $T_{f}$ exhibit two pronounced maxima in $R\left(q_{z}\right) / R_{F}\left(q_{z}\right)$. The position of these maxima is shifted toward smaller $q_{z}$ and their amplitude increases as the temperature decreases bel ow $T_{f}$, which indicates qual itatively that thethickness of the layer and the mean electron density increase in that direction. Figure 8b shows the electron density profiles derived from the reflectivity curves by the modelindependent analysis. I n most respects, the $\rho_{\mathrm{e}}(\mathrm{z})$ profiles calculated by this algorithm agree well with those shown in the inset of Figure 3, which were obtained by fitting a two-box model to the reflectivity data. In all cases, the value of $\rho_{\infty}$ (electron density of the bulk liquid) derived from thefitting procedure $\left(0.27 \AA^{-3}\right)$ agrees with the value calculated from the mass density of pure liquid hexadecane. The profile for $25.1{ }^{\circ} \mathrm{C}\left(\mathrm{T}>\mathrm{T}_{\mathrm{f}}\right)$ comprises a surface layer of slightly enhanced electron density $\left(0.30 \AA^{-3}\right)$ which decays smoothly into the liquid phase, again indicating weak adsorption of the semi-fluorinated alkane at the surfacein thetemperatureregimeof thegaslikefilm above the surface phase transition. The density profiles $\rho_{\mathrm{e}}(\mathrm{z})$ for temperatures below $T_{f}$ exhibit a gradual increase of both the maximum electron density and thickness of the film with decreasing temperature. Even at thelowest accessible temperature (just before bulk freezing of the sample), the maximum electron density in the film is only ca. $0.43 \AA^{-3}$, that is, significantly less than for $\mathrm{F}_{12} \mathrm{H}_{16}$ on $\mathrm{BCH}\left(\rho_{\max } \approx\right.$
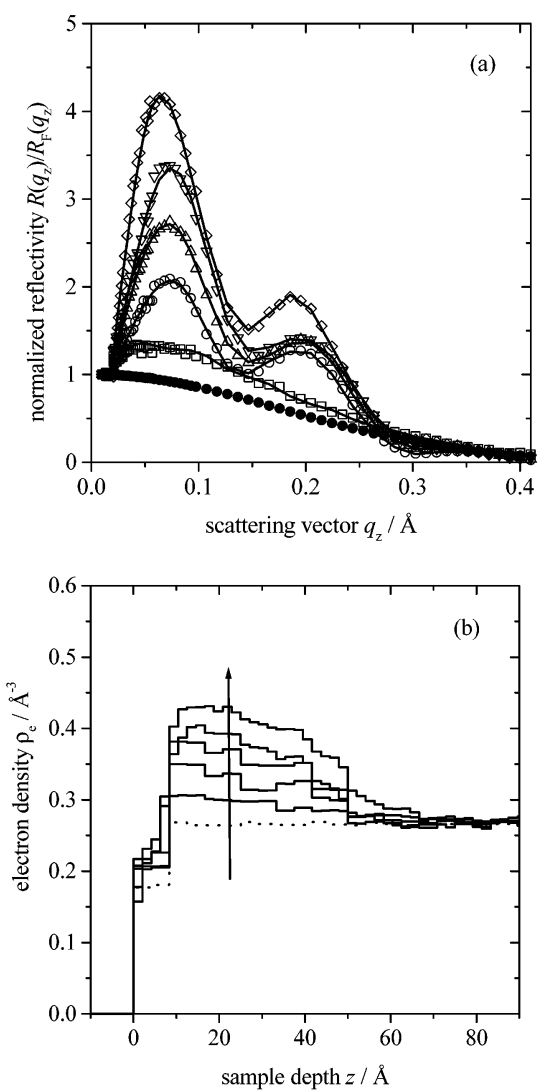

Figure 8. (a) N ormalized X-ray reflectivity $R\left(q_{z}\right) / R_{F}\left(q_{z}\right)$ versus scattering vector $q_{z}$ from the surface of pure hexadecane $(\mathbf{0})$ and a solution of $2.184 \mathrm{mmol} / \mathrm{kg} \mathrm{F}_{12} \mathrm{H}_{16}$ in hexadecane above $\mathrm{T}_{\mathrm{f}}$ $(\square)$ and at four different temperatures below $\mathrm{T}_{\mathrm{f}}: 0,22.3^{\circ} \mathrm{C} ; \triangle$, $20.0^{\circ} \mathrm{C} ; \nabla, 19.3^{\circ} \mathrm{C} ; \diamond, 17.6^{\circ} \mathrm{C}$. Symbol s are experimental data, and the full lines represent best fits obtained from the modelindependent data analysis. (b) Corresponding el ectron density distributions; the arrow indicates the direction of decreasing temperature, and the dotted line corresponds tother eflectivity from the pure solvent.

Table 2. Relative Packing Density $\Theta$ of $F_{12} H_{16}$ in a Hexadecane Solution for Different Temperatures $T$ as Calculated from Equations 3 and $4^{\mathrm{a}}$

\begin{tabular}{ccc}
\hline $\mathrm{T} /{ }^{\circ} \mathrm{C}$ & $\mathrm{C} / \AA^{2}$ & $\Theta=\mathrm{C} / \mathrm{C}^{*}$ \\
\hline 25.1 & 0.9 & 0.12 \\
22.3 & 2.6 & 0.35 \\
20.0 & 4.0 & 0.54 \\
19.3 & 4.9 & 0.66 \\
17.6 & 6.7 & 0.90
\end{tabular}

a The solvent electron density is $\rho_{\mathrm{H}, \mathrm{I}}=0.27 \AA^{-1}$ resulting in a perfect monolayer value of $C^{*}=7.45 \AA^{-2}$. The uncertainties in $C$ and $\Theta$ are less than \pm 1 in the last digit.

$\left.0.65 \AA^{-3}\right)$ and dodecane $\left(\rho_{\max } \approx 0.50 \AA^{-3}\right)$. Integrated surface excess electron densities $\mathrm{C}$ of the $\mathrm{F}_{12} \mathrm{H}_{16}+$ hexadecane system werederived from the density profiles on the basis of eqs 3 and 4 . Values of $C$ and the relative packing density $\Theta=\mathrm{C} / \mathrm{C}^{*}$ for the experimental temperatures are given in Table 2 (using $C^{*}=7.45 \AA^{-2}$ as the surface excess electron density of a perfectly ordered monolayer of $\mathrm{F}_{12} \mathrm{H}_{16}$ on hexadecane).

From the temperature dependence of $\Theta$ in Figure 7, it is seen that the relative packing density of the film increases in a nearly linear way bel ow $T_{f}$ over the entire experimental range, reaching a value of ca. 0.9 at the lowest accessible temperature. The fact that the scan of $R(T) / R\left(T_{0}\right)$ unlike $\Theta$ does not continue to increase but reaches a plateau value bel ow $20^{\circ} \mathrm{C}$ is an artifact, since $R(T) / R\left(T_{0}\right)$ is no longer a measure of the surface excess 
Table 3. Lattice Parameters of the Two-Dimensional $F_{12} H_{m}$ Monolayers on Top of Dodecane and $B C H$ as Determined by GIXDa

\begin{tabular}{lccccccc}
\hline \multicolumn{1}{c}{$\mathrm{m}$} & $\mathrm{T} /{ }^{\circ} \mathrm{C}$ & $\mathrm{q}_{\mathrm{xy}} / \AA^{-1}$ & $\mathrm{~d}_{10} / \AA$ & $\mathrm{A} / \AA^{2}$ & $\mathrm{fwhm} / \AA^{-1}$ & $\xi / \AA$ & $\mathrm{N}$ \\
\hline 14 & 11 & $1.26 \pm 0.01$ & $4.97 \pm 0.05$ & $28.5 \pm 0.3$ & $0.074 \pm 0.003$ & $17 \pm 0.8$ & $3.4 \pm 0.2$ \\
16 & 15 & $1.26 \pm 0.01$ & $4.98 \pm 0.05$ & $28.6 \pm 0.3$ & $0.066 \pm 0.003$ & $19 \pm 0.8$ & $3.7 \pm 0.2$ \\
18 & 21 & $1.26 \pm 0.01$ & $4.96 \pm 0.05$ & $28.4 \pm 0.3$ & $0.059 \pm 0.003$ & $21 \pm 0.8$ & $4.2 \pm 0.2$ \\
$18(\mathrm{BCH})$ & 20 & $1.26 \pm 0.01$ & $4.96 \pm 0.05$ & $28.4 \pm 0.3$ & $0.060 \pm 0.003$ & $20 \pm 0.8$ & $4.1 \pm 0.2$
\end{tabular}

a $\mathrm{T}$ is the experimental temperature, $\mathrm{q}_{\mathrm{xy}}$ is the position of the Bragg peak as depicted in Figure $9, \mathrm{~d}_{10}$ is the corresponding lattice spacing, $A$ is the resulting area per molecule, fwhm is the full width at half-maximum of the peak, $\xi$ is the corresponding correlation length, and $\mathrm{N}$ is the respective number of coherently scattering lattice lines. The error limits result from the uncertainties of the fits of a Gaussian to the in-plane peaks.

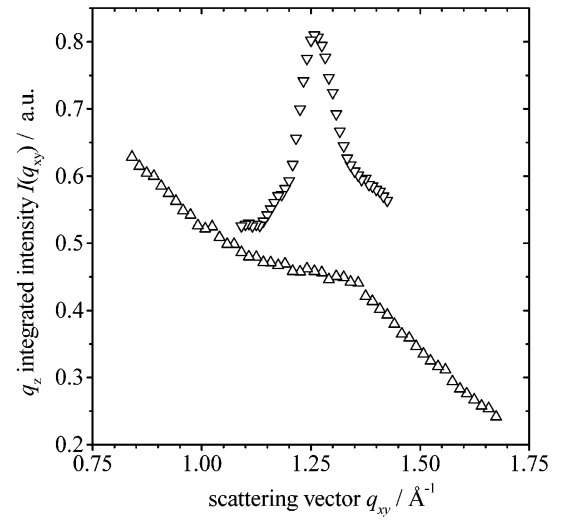

Figure 9. One-dimensional grazing incidence diffraction patterns from the surface of the $\mathrm{F}_{12} \mathrm{H}_{16}+$ dodecane system at $25^{\circ} \mathrm{C}(\triangle)$ and at $15^{\circ} \mathrm{C}(\nabla)$. The symbol s arescattered intensities integrated along the $\mathrm{q}_{\mathrm{z}}$ direction over $0 \leq \mathrm{q}_{\mathrm{z}} \leq 0.1 \AA^{-1}$.

concentration of the adsorbed SFA when the thickness and density of the film (and thus the amplitude and the wavel ength of the undulations in the reflectivity curve, see Figure 8) vary with temperature, as in this case

Grazing Incidence Diffraction. GIXD was used to elucidatethelateral structure of themonolayer films. The general appearance of the recorded diffraction patterns was similar for all systems studied. Thescattered intensity $I\left(q_{x y}\right)$ was derived by integrating over the $q_{z}$ dependence of the scattered intensity in a range $0 \leq q_{z} \leq 0.1 \AA^{-1}$. As a representative example, Figure 9 shows $I\left(q_{x y}\right)$ for a solution of $3 \mathrm{mmol} / \mathrm{kg} \mathrm{F}_{12} \mathrm{H}_{16}$ in dodecane. Above the surface phase transition temperature $\left(T_{f} \approx 18{ }^{\circ} \mathrm{C}\right), \mathrm{I}\left(\mathrm{q}_{\mathrm{xy}}\right)$ falls off in a monotonic way, except for a broad hal o around $\mathrm{q}_{\mathrm{xy}}=1.37 \AA^{-1}$, which is characteristic of liquid n-alkanes. ${ }^{34}$

Below thesurfacephasetransition, a singlepronounced diffraction peak appears in I $\left(q_{x y}\right)$ which was fitted by a Gaussian. The $d_{10}$ spacing of the corresponding 2D lattice is obtained from the position of the Bragg peak as $d_{10}=2 \pi / q_{x y}$, and the area per molecule $A$ is given by $A=2 d_{10} 2 / \sqrt{ } 3$. Results for $d_{10}$ and $A$ for thepresent systems are summarized in Table 3. It is seen that $d_{10}=4.97 \pm$ $0.01 \AA$ for all $\mathrm{F}_{12} \mathrm{H}_{\mathrm{m}}$ materials on both $\mathrm{H}_{12}$ solvents. Slightly higher values, $d_{10}=5.02 \pm 0.05 \AA$, were found for two further semi-fluorinated alkanes, $\mathrm{F}_{14} \mathrm{H}_{14}$ and $\mathrm{F}_{14} \mathrm{H}_{16}$, on dodecane at 20 and $24^{\circ} \mathrm{C}$, respectively..$^{35}$

For the present systems, the GIXD Bragg peaks are rather broad. The full width at half-maximum (fwhm) of the peaks is ca. $0.06 \AA^{-1}$, that is, a factor of 6 greater than theinstrumental resolution $\left(\delta q_{x y} \approx 0.01 \AA^{-1}\right)$. Accordingly, the fwhm is a measure of the positional correlation length $\xi$ of the mol ecules in the film, which can be estimated by therelation $\xi=0.9 \lambda /\left(\mathrm{fwhm} \cos \theta_{c}\right)$, where $\theta_{c}$ is the position

(34) Wu, X. Z.; Sirota, E. B.; Sinha, S. K.; Ocko, B. M.; Deutsch, M. Phys. Rev. Lett. 1993, 70, 958.

(35) Marczuk, P.Ph.D. Thesis, TechnischeUniversität Berlin, Berlin, Germany, 2000.

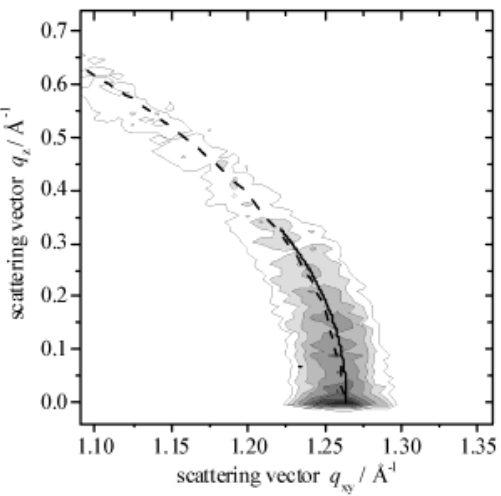

Figure 10. Two-dimensional contour plot of the GIXD intensity from the surface of the $\mathrm{F}_{12} \mathrm{H}_{16}+$ dodecane system bel ow $\mathrm{T}_{\mathrm{f}}$. The data were corrected for the sol vent background scattering. The dashed line is a circular arc according to eq 5 with $\mathrm{d}_{10}=4.98$ $\AA$. The full line is calculated using the exact expression of ref 37 using $\Phi=16^{\circ}$ and a random distribution of the tilt azimuth.

of the peak center. ${ }^{36}$ Values of the correlation length derived in this way (Table 3) aretypically of the order 20 $\AA$, corresponding tojust a few coherently scattering lattice lines in the film. For the systems studied in this work, it is found that $\xi$ increases somewhat with the length of the hydrocarbon tail of the $\mathrm{F}_{12} \mathrm{H}_{\mathrm{m}}$ molecules. Very similar values of $\xi$ are found for $\mathrm{F}_{12} \mathrm{H}_{18}$ in the two $\mathrm{H}_{12}$ solvents.

Figure 10 shows the GIXD intensity of the $\mathrm{F}_{12} \mathrm{H}_{16}+$ dodecane system mapped in a two-dimensional $\left(q_{x y} v s q_{z}\right)$ contour plot. In such a diagram, the scattered intensity is found al ong the rim of a circle centered at $q_{x y}=q_{z}=0$ of radius $\sqrt{ }\left(q_{x y}{ }^{2}+q_{z}{ }^{2}\right)=1.262 \AA^{-1}$. Weidemann et al. ${ }^{37}$ have shown that this kind of scattering pattern can be explained by a 2D arrangement of cylinders which are tilted with respect to the surface normal, if the polar tilt angle $\Phi$ and/or the tilt azimuth $\Psi$ are distributed randomly. For such a geometry, the magnitude of the scattering vectors parallel and perpendicular tothesurface plane, $q_{x y}$ and $q_{z}$, are related to the lattice constant $d_{10}$ in the surface plane approximately by

$$
q_{x y}^{2}+q_{z}^{2}=\frac{4 \pi^{2}}{d_{10}^{2}}
$$

The dashed line in Figure 10 shows this relation using $\mathrm{d}_{10}=4.98 \AA$ as derived from the peak position in Figure 9. As explained earlier, the differencein thecross-sectional areas of the $\mathrm{F}$ and $\mathrm{H}$ blocks of the $\mathrm{F}_{12} \mathrm{H}_{\mathrm{m}}$ molecules causes a tilt of the blocks with respect to each other. If the $\mathrm{F}$ blocks of all molecules were oriented surface normal and the H blocks weretilted with a random tilt azimuth, then one should find an intense Bragg rod resulting from the

(36) Warren, B. E. X-ray Diffraction; Dover: New York, 1990

(37) Weidemann, G.; Brezesinski, G.; Vollhardt, D.; Möhwald, H Langmuir 1998, 14, 6485. Weidemann, G.; Brezesinski, G.; Vollhardt D.; De Wolf, C.; Möhwald, H. Langmuir 1999, 15, 2901. 
$F$ block, with a half-width in thez direction corresponding tothelength of theF block (i.e., $0.2-0.3 \AA^{-1}$ ), superimposed on a weak ring resulting from the tilted $\mathrm{H}$ blocks. The GIXD contour in Figure 10 does not support such a structure model of vertically oriented $\mathrm{F}$ blocks, as the diffracted intensity appears to be distributed al ong a curve, even for small values of $q_{z}$.

From the fact that the cross-sectional area of the $F_{12}$ blocks in the film exceeds the respective value for poly(tetrafluoroethylene) (PTFE) $\left(27.4 \AA^{232}\right.$ ) by ca. $4 \%$, one estimates a tilt angle of theF blocks $\Phi_{\mathrm{F}}$ against thesurface normal of $16^{\circ}$. The exact relation between $q_{z}$ and $q_{x y}$ (eqs 4 and 12 in ref 37a) yields the full line in Figure 10 for this value of $\Phi_{F}$, if a random distribution of thetilt azimuth is assumed. This model could explain in part the very high degree of disorder in the Gibbs film.

\section{Discussion}

$\mathrm{F}_{12} \mathrm{H}_{\mathrm{m}}$ Films on $\mathbf{H}_{12}$ Solvents. Theresults of this study confirm earlier reports that Gibbs films of semi-fluorinated alkanes at the surface of liquid hydrocarbons may exhibit a sharp phase transition from a gaslike state to a dense monolayer phase. $F$ or the present series of $F_{12} \mathrm{H}_{\mathrm{m}}$ molecules $(\mathrm{m}=14,16,18)$, a sharp surface phase transition is observed for sol utions in dodecaneand bicyclohexyl. This transition is seen in the temperature dependence of the surface tension as well as the X-ray reflectivity. The integral surface excess electron density $C$ derived from the reflectivity data indicates that this transition occurs froma dilutegasl ikefilmabovethetransition temperature $T_{f}$ to a nearly close-packed monolayer below $T_{f}$. The packing of the molecules in the film is characterized by the relative packing density $\Theta=C / C^{*}$, which relates the packing density of the real film to that of a hypothetical perfectly ordered close-packed monolayer in which the hydrocarbon tails of the SFA molecules are tilted by ca. $45^{\circ}$ to allow a close packing of both the fluorocarbon and hydrocarbon chains. In the series of $\mathrm{F}_{12} \mathrm{H}_{\mathrm{m}}$ compounds on dodecane, $\Theta$ increases from ca. $0.8\left(F_{12} \mathrm{H}_{14}\right)$ to $1.0\left(\mathrm{~F}_{12} \mathrm{H}_{18}\right)$ (Table 1). This increase of $\Theta$ with the length of the hydrocarbon tails of $\mathrm{F}_{12} \mathrm{H}_{\mathrm{m}}$ mol ecules can be attributed to an increasing attractive lateral interaction between hydrocarbon tails in the film, which stabilizes a dense Gibbs film. The same trend of $\Theta$ with increasing hydrocarbon chain length is seen for $\mathrm{F}_{12} \mathrm{H}_{16}$ and $\mathrm{F}_{12} \mathrm{H}_{18}$ on $\mathrm{BCH}$.

For given members of the $\mathrm{F}_{12} \mathrm{H}_{\mathrm{m}}$ family, the properties of the low-temperature phase at the surface of dodecane and $\mathrm{BCH}$ are not much different. One notes that for both $\mathrm{F}_{12} \mathrm{H}_{\mathrm{m}}$ compounds for which such a comparison has been made, higher values of $\Theta$ are found for the adsorption from the gl obular hydrocarbon $(\mathrm{BCH})$ in comparison with the linear-chain alkane (dodecane). We attribute this differencetothe different strength of interaction of $\mathrm{F}_{12} \mathrm{H}_{\mathrm{m}}$ molecules with the two solvents: Specifically, a more attractive interaction of dodecane, in comparison with $\mathrm{BCH}$, with the alkane blocks of the $\mathrm{F}_{12} \mathrm{H}_{16}$ and $\mathrm{F}_{12} \mathrm{H}_{18}$ molecules may be due to a correlation of molecular orientations between hydrocarbon chains of the solvent and the solute in dodecane. This effect is expected to be even stronger in the case of $\mathrm{F}_{12} \mathrm{H}_{16}$ in hexadecane where the free energy penalty due to the chain length mismatch vanishes, ${ }^{38}$ becausethechain length of thesolvent matches thelength of thehydrocarbon tails of the $\mathrm{F}_{12} \mathrm{H}_{16}$ molecules. We return to this point later.

The GIXD results indicate a 2D hexagonal packing of the $\mathrm{F}$ blocks in the plane perpendicular to the block axis,

(38) Wu, X. Z.; Ocko, B. M.; Tang, H.; Sirota, S. B.; Sinha, S. K.; Deutsch, M. Phys. Rev. Lett. 1995, 75, 1332. which may however betilted by a small tilt angle $\phi \leq 16^{\circ}$ with respect tothe surface normal . Thelatticespacing $d_{10}$ is $4.97 \pm 0.01 \AA$, independent of the chain length of the $\mathrm{F}_{12} \mathrm{H}_{\mathrm{m}}$ compounds. This value is about $2 \%$ larger than the lattice spacing in PTFE $\left(\mathrm{d}_{10}=4.87 \AA^{32}\right)$ and the hightemperature bulk phase of pure $\mathrm{F}_{12} \mathrm{H}_{\mathrm{m}}$ compounds with $\mathrm{m}<14 .{ }^{11}$ Thearea per moleculein the close-packed phase of the Gibbs film as obtained from the GIXD measurements, $A=2 \mathrm{~d}_{10}{ }^{2} / \sqrt{ } 3=28.6 \AA^{2}$, is similar to the $27.6 \AA^{2}$ observed for the surface-frozen layer of the pure SFA. ${ }^{26}$ However, it is significantly lower than the mean area of $34 \pm 2 \AA^{2}$ derived from the surface tension isotherms of $\mathrm{F}_{12} \mathrm{H}_{18}$ on dodecane. We attribute this difference to the short-range nature of the positional order in the Gibbs monolayer. Table 3 shows that the in-plane positional correlation length $\xi$ is of the order of $20 \AA$, that is, smaller by several orders of magnitudethan in the surface-frozen monolayer of long-chain n-alkanes. ${ }^{12}$ Table 3 alsoindicates that $\xi$ increases somewhat with the chain length of the $\mathrm{F}_{12} \mathrm{H}_{\mathrm{m}}$ molecule and is not significantly affected by the nature of the hydrocarbon solvent. Although not very pronounced, both of theseeffects arein linewith thetrends observed for the relative packing density $\Theta$ (Table 1 ).

The electron density profiles $\rho_{\mathrm{e}}(\mathrm{z})$ derived from the XR curves of the present systems generally exhibit a maximum near the outer surface of the film (see, for instance, Figure3) indicating that the $\mathrm{F}_{12} \mathrm{H}_{\mathrm{m}}$ molecules areoriented with the $F_{12}$ block pointing to the vapor phase. The excess electron density is smeared out over a width of ca. $40 \AA$ for the films on BCH (Figure 6) and at least $50 \AA$ for the films on dodecane (Figure 5). Since the excess electron density arises al most entirely from the fluorinated block, which has a length of $16.7 \AA$, the centers of the $F_{12}$ blocks in the film cannot be aligned in a plane but must be distributed over a region of $20-30 \AA$ in the $z$ direction, like in a smectic $C$ film. Such an up-down staggering of the molecul es over a lateral length scale of either a single or several mol ecular diameters has been observed in bulk perfluoral kanes ${ }^{39}$ in the low-temperature solid phases of the pure $F_{12} \mathrm{H}_{\mathrm{m}}$ with $\mathrm{m}=8,10$, and $12^{11}$ and for thesurfacefrozen layer of pure $\mathrm{F}_{12} \mathrm{H}_{8}$ and $\mathrm{F}_{12} \mathrm{H}_{14}{ }^{26}$ Onemay speculate further that staggering of tilted segments leads to a local buckling of the SFA layer, as suggested for the surfacefrozen layer of $\mathrm{F}_{12} \mathrm{H}_{19}{ }^{26}$

$\mathbf{F}_{\mathbf{1 2}} \mathbf{H}_{\mathbf{1 6}}$ on $\mathbf{H}_{\mathbf{1 6}}$. Gibbs films of $\mathrm{F}_{12} \mathrm{H}_{16}$ on hexadecane exhibit a more complex behavior than observed with any of the $\mathrm{F}_{12} \mathrm{H}_{\mathrm{m}}$ compounds on dodecane or $\mathrm{BCH}$. From the temperature dependence of $\Theta$ (Figure 7), it is seen that the transition from the gaslike state at high temperature to a condensed monolayer does not occur in one step, as in the adsorption from dodecane (Figure 4). Instead, $\Theta$ increases gradually as the temperature decreases below $23.5^{\circ} \mathrm{C}$, and a surface concentration corresponding to a close-packed monolayer $(\Theta \approx 1)$ has not been reached when freezing of the bulk sample eccurs at $17.6^{\circ} \mathrm{C}$. Theabsence of a phasetransition of theGibbs filmin this system cannot be due solely to the solute, as the films of $\mathrm{F}_{12} \mathrm{H}_{16}$ on dodecane and $\mathrm{BCH}$ do exhibit a sharp phase transition. Obviously, the properties of the solvent $\mathrm{H}_{16}$ and the interactions between $\mathrm{F}_{12} \mathrm{H}_{16}$ and $\mathrm{H}_{16}$ must play a role.

We conjecture that the absence of a first-order phase transition in this system is a consequence of the strong attractive lateral interaction between $\mathrm{H}_{16}$ chains when they are arranged side-by-side in their all-trans conformation. This lateral interaction between higher $\mathrm{n}$-alkane molecules is the main cause for the surface-freezing at

(39) Strobl, G.; Elben, H.; J aeger, R.; Kimmig, M.; Steiner, R.; Schwickert, H.; Ritter, C. J . Chem. Phys. 1991, 95, 2807. 
the free liquid surface ${ }^{12,40,41}$ and a related prefreezing phenomenon at the interface against atomically flat surfaces such as graphite. ${ }^{42,43}$ Surface-freezing requires a minimum chain length of 15 (theoretical prediction) to 16 (experimental data) carbon atoms for pure alkanes. ${ }^{12}$ A partial alignment of alkane chains, similar to the correlation of molecular orientations of long-chain nalkanes in the pure liquid state, ${ }^{18}$ is expected to occur between the $\mathrm{H}_{16}$ tail of $\mathrm{F}_{12} \mathrm{H}_{16}$ molecules and the $\mathrm{H}_{16}$ solvent. This effect can be seen as a solvation of the oleophilic block of SFA in al kane solvents. It is expected to be more pronounced in hexadecane than in dodecane, as the length of the $\mathrm{H}_{16}$ molecule (ca. $22 \AA$ ) matches that of the alkane blocks of $\mathrm{F}_{12} \mathrm{H}_{16}$. F or geometrical reasons, such a solvation of the $\mathrm{F}_{12} \mathrm{H}_{16}$ molecules does not permit a close packing of their $\mathrm{F}_{12}$ blocks in the Gibbs film. As the energy gain of the close packing of the fluoroalkane blocks of SFA is thought to be the main driving force for their surface phase transition at $T_{f}$, the solvation of the alkane block by $\mathrm{F}_{12} \mathrm{H}_{16}$ can prevent a sharp (first-order) phase transition. In this case, the energy gain connected with the microphaseseparation of alkaneand fluoroalkane blocks will cause a gradual increase of the surface concentration of SFA with decreasing temperature, as observed for $\mathrm{F}_{12} \mathrm{H}_{16}$ in $\mathrm{H}_{16}$ solutions.

As in solutions of the $\mathrm{H}_{12}$ solvents, the excess electron density of the Gibbs films of $\mathrm{F}_{12} \mathrm{H}_{16}$ on $\mathrm{H}_{16}$ is smeared out over a region broader than the length of the $F_{12}$ block, indicating a staggering of the molecules. A detailed interpretation of the $\rho_{\mathrm{e}}(\mathrm{z})$ profiles of this system (Figure 8b) in terms of the packing of the molecules is not possible. In particular, it is not known if, or to what extent, desolvation of the alkane blocks and cl ose packing of the fluorocarbon blocks (possibly connected with a tilting and close packing of the alkane blocks) occur as the temperature is lowered. In particular, the origin of the longrange tail of $\rho_{\mathrm{e}}(\mathrm{z})$ seen at the lowest experimental temperature $\left(17.6^{\circ} \mathrm{C}\right)$ is not known.

In the earlier study of the $\mathrm{F}_{12} \mathrm{H}_{16} / \mathrm{H}_{16}$ system, ${ }^{15}$ the evolution of surface states was monitored by surface tension measurements in a temperature range from 16 to $40{ }^{\circ} \mathrm{C}$ and for $\mathrm{F}_{12} \mathrm{H}_{16}$ concentrations up to $5 \mathrm{mmol} / \mathrm{kg}$. The results weresummarized in a $\gamma-$ T phasediagram (Figure 6 in ref 15) showing the putative regions of stability of the surface-frozen phase of $\mathrm{F}_{12} \mathrm{H}_{16}$ and of three monolayer phases of $\mathrm{F}_{12} \mathrm{H}_{16}$ (gaslike, liquid expanded, and condensed). According to that phase diagram, surface-freezing of $\mathrm{H}_{16}$ occurs at the surface of dilute sol utions ( $C<C_{E} \approx 1.3 \mathrm{mmol} /$ $\mathrm{kg}$ ) at temperatures below the surface-freezing temperature of pure $\mathrm{F}_{12} \mathrm{H}_{16}\left(17.6^{\circ} \mathrm{C}\right)$, but a transition from the gaslike phase to the condensed phase of $\mathrm{F}_{12} \mathrm{H}_{16}$ occurs at concentrations $C>C_{E}$. For even higher concentrations (C $>\mathrm{C}_{\mathrm{T}} \approx 1.4 \mathrm{mmol} / \mathrm{kg}$ ), it was concluded that the transition from the gasliketothe condensed phase of the Gibbs films involves two distinct surface phase transitions, with a liquid expanded phaseexisting in the temperaturerange from $T_{f}$ (gas/liquid expanded transition) to $T_{c}$ (liquid expanded/condensed transition). In light of the present

(40) Earnshaw, J . C.; Hughes, C. J . Phys. Rev. A 1992, 46, R4494. (41) Deutsch, M.; Wu, X. Z.; Sirota, E. B.; Sinha, S. K.; Ocko, B. M.; Magnussen, O. M. Europhys. Lett. 1995, 30, 283.

(42) Kern, H.; v. Rybinski, W.; Findenegg, G. H. J Colloid Interface Sci. 1977, 59, 301.

(43) Grosse-Rhode, M.; Findenegg, G. H.J Colloid I nterfaceSci. 1978, 64, 374. work, this putative phase diagram has to be modified in the sensethat at concentrations $c>c_{T}$ thetransition from the gaslike to the condensed state of the film proceeds in a continuous way as the temperature is lowered. No XR data exist for moredilute concentrations $\left(c<c_{T}\right)$ for which the phase diagram predicts a single first-order phase transition. In that case, the coexistenceline of the gaslike and condensed phases would terminate in a 2D critical point (instead of the triple point of the putative phase diagram). Alternatively, the transition from the gaslike tothe condensed state of the Gibbs film may becontinuous down to the lowest experimental temperatures. Further $X R$ measurements for dilutesulutions of $\mathrm{F}_{12} \mathrm{H}_{16}$ in $\mathrm{H}_{16}$ are needed to resolve this question.

\section{Conclusions}

We have studied Gibbs films of $\mathrm{F}_{12} \mathrm{H}_{\mathrm{m}}(\mathrm{m}=12,14,16$, 18) at the free liquid surface of their solutions in two n-alkanes (dodecaneand hexadecane) and in bicyclohexyl. For the two $\mathrm{H}_{12}$ solvents, sharp first-order phase transitions from a gasl ike to a condensed state of the Gibbs film were observed. $\mathrm{F}$ or $\mathrm{H}_{16}$, however, which shows surfacefreezing in the pure state, a gradual transition from the gaslike to the condensed state of the film was found. This different behavior is explained tentatively in terms of three types of interactions in those systems: (a) the mutual antipathy between hydrocar bon and fluorocarbon chains, which drives the adsorption of the SFA molecules at the surface of thesolutions in alkanes; (b) theattractivelateral interaction between the fluorocarbon blocks of the SFA molecules in the surface; and (c) the related effect of a strong lateral interaction between the hydrocarbon block of theSFA molecules and long-chain alkanes such as $\mathrm{H}_{16}$ (and, to a much lesser degree, $\mathrm{H}_{12}$ ), which causes a solvation of the alkane block of the SFA. These effects, in combination with thegeometrical incompatibility between the two blocks of SFA molecules, can explain the main features observed in this study.

The Gibbs films of $\mathrm{F}_{12} \mathrm{H}_{\mathrm{m}}$ with $\mathrm{m} \geq 14$ on dodecane and bicyclohexyl, which show first-order phase transitions at a concentration-dependent temperature $T_{f}$, form a condensed phase in which the $F_{12}$ blocks are arranged in $2 D$ hexagonal arrays, with a small tilt angle against the surface plane $\left(\Phi \leq 16^{\circ}\right)$. The hexagonal order persists on short length scales only, with an in-plane positional correlation length of only a few molecular diameters. Furthermore, the electron density profiles indicate that the centers of mass of the $F_{12}$ blocks are not arranged in a plane but spread out over some distance, possibly due to a staggered arrangement of the molecules.

The anomal ous behavior of the Gibbs films of $\mathrm{F}_{12} \mathrm{H}_{16}$ on $\mathrm{H}_{16}$, for which a continuous transition from the gasl ike to the condensed film is observed, is attributed to the solvation of thealkaneblock of theSFA by thehydrocarbon solvent. This system shows that this solvation effect can have a pronounced effect on the state of Gibbs films and may induce qualitative changes of the phase behavior of such systems.

Acknowledgment. Wethank K. Kjaer for his hel pat theBW1 beaml ine of HASYLAB/DESY in Hamburg. This work was supported by the DF G through the Sfb 448 and through the Schwerpunktprogramm "Benetzung und Strukturbildung an Grenzflächen" (Fi 235/13).

LA025596D 